\title{
POPULATION PROJECTION AND POLICY IMPLICATIONS FOR EDUCATION: \\ A DISCUSSION WITH REFERENCE TO KERALA
}

P.K. Michael Tharakan \& K. Navaneetham

Working Paper No. 296

June 1999 



\title{
POPULATION PROJECTION AND POLICY IMPLICATIONS FOR EDUCATION: A DISCUSSION WITH REFERENCE TO KERALA
}

\author{
P. K. Michael Tharakan \\ and \\ K. Navaneetham \\ Centre for Development Studies \\ Thiruvananthapuram
}

June 1999

An earlier version of this paper was presented at an internal seminar in the Centre for Development Studies and in a Workshop on Major Issues in School Education with reference to Protected Teachers, Uneconomic Schools, School Age Population, Teacher Pupil Ratio etc. organised by the Kerala State Planning Board on 18 July 1998. We are grateful to the participants at both these sessions and to an unknown referee for their 


\section{ABSTRACT}

In the context of high levels of public expenditure, already committed to the educational sector in States like Kerala, it is argued that there should be restrictions on further investment. Such arguments are apparently supported by the fact that the birth rate is declining and therefore it will result in lesser number of school age population. Since this trend directly affect the elementary education sector-the most sensitive- it is important to project the school age populations with realistic assumptions. This study uses the recent information on the trends in fertility and reproductive preferences to make a realistic future assumption on fertility. Since the total fertility rate (TFR) is distorted by the changes in the timing of child bearing, the initial level of TFR was adjusted in the projection assumption. Among the three assumptions used (high, medium and low) the medium variant shows that the fall in school going age population will be around 3.29 lakhs between 1991 and 2001 . However, there will be an increase in the school age population of around 2.37 lakhs between 2001 and 2006 and 1.54 lakhs between 2001 and 2011. Therefore, the fruits of fertility decline will be realized fully after the year 2011 only. In that context, built up school space should not be diverted for use outside schooling purposes; but should be used within the same sector for qualitative upgradation. Decelerating birth rate and its expected impact upon primary school enrolment, by itself cannot be considered as cause enough to withdraw public investment. Such overall impact will hide within it, level-wise changes of demand for education, from lower to higher school classes, particularly within the relatively educationally 'backward' districts and communities. Therefore, the decelerating birth rate should be carefully monitored. Taking into account its trend and location, further public investment should be reoriented and rationalized. To close schools purely on the basis of decelerating demographic trends will be counterproductive to the nationally and internationally accepted objective of education for all.

JEL Classification: I2, I20

Key Words: population projection, uneconomical schools, school age population, educational planning, education policy, Kerala 


\section{Introduction}

The World Conference on Education for All (WCEFA) in Jomtein, Thailand, in March 1990, and the summit of nine highly populous countries in Delhi, in December 1993, have set the goal of minimum level of basic education for all persons by the year 2000 or thereabouts. This target was evolved upon a consensus about positive interaction between education and development. Education can play a crucial role both in enlarging peoples' income-earning opportunities and in enabling them to achieve a better quality of life at a given level of income [Dreze. J and Saran. M, 1993, 5]. The argument that education is to be considered as a fundamental right is gathering strength. This idea is embodied in the proposed $83^{\text {rd }}$ constitutional amendment introduced in the Rajya Sabha in July 1997 [PROBE/CDE, 1999, 1]. The target of a minimum level of basic education enjoins upon governments to make priority investments in the sector of primary education. Literacy programmes like Total Literacy Campaigns [TLC] are equally important for attaining Education For All (EFA). A significant component of the TLC is oriented towards adult population. Such programmes depend upon voluntary action and efforts of Non-Governmental Organisations (NGOs) along with coordination by Governmental bodies [see Tharakan, P.K.M, 1990]. In the case of primary education, public responsibility cannot be avoided. In 
this sector, the most significant component of educational transaction is through formal institutions. The principal institutional mechanism for developing human skill and knowledge is through the formal educational system. Formal institutional instruction requires school buildings and other accessories, teachers' training, teaching and learning materials etc. These can be provided by government and non-governmental agencies; as the educational history of Kerala State shows [Tharakan, P.K.M, 1984]. Since in developing societies, the clientele for primary education come mostly from economically weaker sections, private activity guided by market signals alone cannot provide effective basis for its promotion [Dreze. J. and Saran. M, 1993, 7-8; World Bank, 1991, 11]. Education at the elementary level cannot be expanded solely based on short run economic considerations. It is understandable that governments will share the responsibility of mobilizing resources for achieving EFA with NGOs and voluntary and private agencies. The elementary education sector is too important to be left to the market forces alone and it should come under the direct control and responsibility of the governments [Varghese, N.V, 1991, 186-197]. Whatever be the merits of NGOs, voluntary and private organisations, they cannot be expected to replace government investment in total, in providing institutional and infrastructural requirements for a major target like EFA. The ultimate responsibility will be that of the government.

States like Kerala [which have already done well in elementary education], seems to earmark a portion of responsibility for further promotion to private [i.e., non-government] agencies. With the State spending 29.5 per cent of its budgeted expenditure and 7.5 per cent of its State Domestic Product [SDP] for education in 1993-94 [MOHRD, 1994], Kerala's public resources are heavily committed already to education. Kerala's per capita government expenditure on education is also very high and is way ahead of the all-India average [Tyagi, P.N., 1991, p.114]. 
On the other hand, there are evidences that private educational institutions do well in inparting education ${ }^{1}$. Already, there are several arguments on the basis of micro-level efficiency and of short-term financial gains in favour of privatisation of educational institutions [Shah, K.R, 1993, 215222]. In this context it will be rational to streamline and restrict public expenditure found avoidable in education. The Kerala State Resource Commission [KSRC] identified 'uneconomical' schools' in early 1990s on the basis of low enrolments. There was a subsequent decision of the Directorate of Public Instruction [DPI] to close down some schools. This can be seen as a step towards rationalising government expenditure in education. The schools recommended for closure and the schools actually closed; include private (government aided) schools as well. In Kerala, from 1957 onwards, major expenditure like maintenance grant and teachers' salary, of all private schools, except the unaided schools, are

1 There are observations from different parts of India about "better" products of private education. With regard to secondary education in Colombia, the Dominican Republic, the Philippines, Tanzania and Thailand it was found that private school students generally outperform public school students on standardised marks and language tests, even after holding constant for the fact that on an average, private school students come from more advantaged backgrounds than their public school counterparts [Paqueo, U. 1991, 205-218].

The exact number of schools identified as 'uneconomical' on the basis of low enrolment are not known accurately. The Malayala Manorama (6 March, Saturday, 1993) reported that the State Resource Commission recommended that 485 schools identified as uneconomical are to be closed immediately. The same newspaper reported [Malayala Manorama, 19 May, Tuesday, 1992] that a three member committee headed by DPI recommended that only 87 from the 607 schools identified as uneconomical are to be closed. They wanted schools run by local bodies and Fisheries and Tribal schools to be deleted from the list of schools to be closed. According to the estimate of the committee around 2000 students will have to find readmission if these 87 schools are closed. They are to be accommodated by government or Aided schools. Around 600 teachers who are likely to be out of work are to be "protected" and are to be accommodated by government schools. Those working in corporate management schools should be accommodated by the same management in other schools. The policy of closing 'uneconomical schools' seems to have changed or suspended for the time being. 
borne by government [Mathew, A, 1987, 174-175]. Running such schools involve considerable financial responsibility for the Government since the financial returns in terms of fees from these schools as well as from government schools are very low. Therefore it was reasonable to decide that financial responsibility of the governemnt should be restricted by closing such schools which are bound to be unsustainable. On the other hand, it was also reasonable to let unaided private schools with less governmental financial responsibility and supervision to be continued ${ }^{3}$.

There could be also a demographic argument for lessening public investment in basic education. The population growth rate in India as a whole was at its peak in 1961-81, with growth rate being 2.2 per cent per annum. In 1971-81 fertility started declining and during the decade 1981-91, the rate of population growth declined to 2.1 per cent [GOI, MOHRD, 1993, 9]. The consequent deceleration has differed from region to region [see Prakash. S and Debal.P, 1992, 139-153]. Kerala being a State with perceptible deceleration in population growth, and having already high literacy rates, there are strong arguments for reducing government expenditure on elementary education on strictly demographic grounds. The Kerala State Planning Board which was in position from 1991 to 1996 commissioned studies in this regard and at least one such study has recommended reduction of the number of schools and governmental investment [SPB, 1994]. Such a policy measure is also

3 The previous minister of Education of Kerala while answering a calling attention motion had reportedly said in the Kerala legislature that in places where they will not disturb the functioning of government, or aided schools, unaided schools can be allowed [Malayalam Manorama, 17 March, Wednesday, 1993]. In another occasion he has stated that whatever be the financial problems of the state, aided and unaided schools will be permitted [Malayalam Manorama, 23 August, Monday, 1993]. It will be worthwhile to see whether the unaided schools allowed in recent years have followed any such criteria or not. The 1987-1991 ministry headed by Sri. E. K. Nayanar did not allow any new unaided schools. 
suggested by the World Bank Study on Primary Education in India [WB, 1997, 50-51]. In the context of such strong arguments we are undertaking an exercise here to project population trends for Kerala, to see what kind of policy formulations are necessary and feasible with regard to public investment in education. Whether a decelerating trend in school going age population alone should automatically lead to reduction of educational facilities or not, is also examined. This question is attempted to be answered in the over-all context of nationally and internationally committed targets of EFA.

\section{Population Projection of Kerala}

In this section, we project the population up to the year 2026. From the projected population, we derive the school age population (5-14) in single year age. The smoothed age- sex distribution of 1991 census is used as a base year population [Registrar General, 1996]. Projections are made for every five years since 1991. We have used PEOPLE projection software and it uses the cohort component method for projecting the population by age and sex. For more details on the software and the method, please see Groenewold and Navaneetham, 1998. The important aspect in the population projection is to formulate a realistic future assumption on the fertility, mortality and migration trends and patterns. Although we do not exactly know what the likely future levels and patterns in the three components, we may be able to develop assumptions with good approximation on the basis of the current and past information.

\subsection{Fertility Assumption}

Realistic assumptions on future fertility levels are important and crucial to make inferences about the future size and structure of the population, particularly at the school going age populations. We have 
made three different projections namely high variant, medium variant and low variant based on three fertility assumptions in order to have a lower and upper limits of the future school age population.

Total fertility rate 4 in Kerala started declining since 1960 onwards and reached the level of 2.6 per woman in 1981-85 (Bhat, P.N.M and Rajan, S.I, 1990). According to the estimates given by Sample Registration System (SRS), this has reached 1.7 in 1994, which is below the replacement level. However, the National Family and Health Survey (NFHS) show that total fertility rate was 2.0 per woman during 1990-92 [Nair, P.S. et al. 1994]. As Kerala has reached the replacement level, the question is whether the same decline in TFR will continue in the future. There are indications that fertility decline slowed down in the districts where the level is at the replacement level. Table I give the trend in TFR in the three districts namely Ernakulam, Palakkad and Malappuram. In all the three districts, decline of total fertility rate has slowed between the period 1981-86 to 1986-91 compared to 1976-81 to 1981-86. There was no decline in TFR in the district of Ernakulam during 1980s due to the fact that it already reached the replacement level fertility.

Total fertility rate (TFR) is a hypothetical measure which is defined as the average number of births a woman would have if she were to live through her reproductive years and bear children at each age at the rates observed in a particular year. This measure is affected by the changes in the timing of childbearing during the period in which the TFR is measured. Therefore, a change in the rate at which people are having children in a given year can no longer be taken as an indication of a change in the number of children they will bear altogether in the course of the reproductive lives [Hajnal, 1947]. Consequently, future assumptions based on the conventional TFR without adjusting the temporal component may lead to unrealistic future assumptions and distort the projection results and its implications. 
Table I. Trends in total fertility rate in selected districts of Kerala

\begin{tabular}{|c|c|c|c|c|c|}
\hline \multirow[t]{2}{*}{ Districts } & \multicolumn{3}{|c|}{ TFR } & \multirow{2}{*}{$\begin{array}{c}\% \text { decline } \\
\text { between } 1976-81 \\
\text { to } 1981-86\end{array}$} & \multirow{2}{*}{$\begin{array}{l}\% \text { decline } \\
\text { between 1981-86 } \\
\text { to } 1986-91\end{array}$} \\
\hline & 1976-81 & $1981-86$ & 1986-91 & & \\
\hline Ernakulam & 3.39 & 2.13 & 2.12 & 37 & Negligible \\
\hline Palakkad & 4.37 & 3.23 & 2.78 & 26 & 14 \\
\hline Malappuram & 5.76 & 4.37 & 3.67 & 24 & 16 \\
\hline $\begin{array}{l}\text { Three dist. } \\
\text { combined }\end{array}$ & 4.49 & 3.22 & 2.84 & 28 & 12 \\
\hline
\end{tabular}

Source: Zachariah, K.C. et al. (1994).

One method to project the future fertility is to analyse the desire for additional children and current desired family size preferences of couples. Table II gives the fertility preferences of currently married women according to the number of living children from NFHS, 199293. On the whole, 28 percent of women say that they want another child. Among those who had one child, 80 per cent of them said that they want to have another child in the future. Therefore, it is clear that majority of them prefer to have at least two children. Also another survey (Zachariah , K.C. et al, 1994 ) indicates that only 21 percent of women without surviving sons reported that they do not want to have an additional child. In other words, it is evident that most couple wants to limit their family size with at least two children after having a son ${ }^{5}$. When asked about the ideal number of children that they wanted it was reported that an average of 2.6 children were considered an ideal in Kerala. Those women who have either no child or one child have reported that 2.3 and

5 It is also observed from the Kerala Fertility survey [Zachariah. K.C et al. 1994] that women who go for the permanent method of population control (sterilization) had an average of 2.8 surviving children in Ernakulam (1.5 boys and 1.3 girls), 3.4 children in Palakkad (1.7 boys and 1.7 girls) and 3.9 surviving children in Malappuram (2.1 boys and 1.8 girls). 
2.2 children respectively would be their ideal family size. The same question was asked to the younger women and it was reported that the ideal family size would be 2.6 children among women in the age group 15-19 and 2.7 children among the women in the age group 20-24. These young women are going to determine the future levels of fertility. The Kerala Fertility Survey [Zachariah K.C. et al., 1994] also shows that the desired family size for the women in the age group of 15-19 is around 2.7 children (an average in the three surveyed districts namely Ernakulam, Palakkad and Malappuram). Even in Ernakulam where we have already achieved total literacy, women in this age group reported that they wanted to have an average of two children. Allowing for changes in the attitude towards children in future due to changes in their socio-economic conditions, the total fertility rate can be lower than the desired family size reported now. Hence, if the desired family size is 2.5 children, now, they will be ending up having at least two children in their reproductive life in the next 30 years.

Table II. Distribution of currently married women by desire for children according to number of living children, 1992-93, Kerala

\begin{tabular}{|l|c|r|r|r|r|}
\hline \multirow{2}{*}{$\begin{array}{l}\text { Desire for } \\
\text { additional }\end{array}$} & \multicolumn{5}{|c|}{ Children surviving } \\
\cline { 2 - 6 } children & 0 & 1 & 2 & $3+$ & Total \\
\hline Want more & 85.8 & 80.0 & 13.0 & 6.8 & 28.0 \\
Want no more & 1.5 & 11.2 & 26.8 & 17.9 & 19.3 \\
Sterilized & 2.2 & 5.3 & 57.2 & 71.5 & 48.3 \\
Undecided/upto & & & & & \\
god & 3.3 & 1.3 & 2.0 & 2.2 & 2.4 \\
Infecund & 6.6 & 2.1 & 0.6 & 1.3 & 1.8 \\
Missing & 0.7 & - & 0.3 & .6 & .2 \\
\hline Total & 100 & 100 & 100 & 100 & 100 \\
\hline
\end{tabular}

Source: National Family Health Survey 1992-93, Kerala 
We have made three fertility assumptions namely high, medium and low variant. The medium variant is the most likely trend in the future level of fertility. The other two variants considered as realistic upper and lower limits of the future fertility trends. In the high variant projection, we assume that the total fertility rate will remain constant at the level of 2.0 per woman throughout the projection years. In the case of medium variant, we assume that there will be a slow decline in TFR and reach the level 1.8 per woman in 2011 and thereafter remain constant. In the low variant, it is assumed that TFR will decline moderately and will reach the level of 1.6 in 2001 and remain constant thereafter.

In all the three variants, we have taken the TFR level of 2.0 during the base period 1991-96 eventhough the estimates from SRS indicate the level of 1.7 in 1994. Since TFR is distorted by the changes in the timing of childbearing (increase in the mean age at childbearing of various birth order), it has to be adjusted by eliminating the temporal component. If we make assumptions based on current low level fertility into the future, it will be misleading the true size of the school age population and other implications in the future. The tempo adjusted total fertility rate gives the better understanding of the level and trends of past fertility and provides a firmer basis for projecting trends in future fertility [For more details, please see Bongaarts and Feeney, 1998). The analysis carried out by Bongaarts and Feeney (1998) for Taiwan indicates that the conventional TFR is .25 births lower than the tempo-adjusted TFR in the early 1990s. The NFHS 1992-93 reports that median age of childbearing in Kerala for the first births increased from 20.9 for the age group of women 45-49 to 22.3 for the age group of women 25-29 (Nair, P.S., 1995). This gives an indication that mean age at childbearing has been increasing and might have contributed for depressing the total fertility rate. Therefore, in our analysis we have assumed a TFR level of 
2.00 during the period 1991-96 ( approximately 0.25 births above the observed level of TFR).

Table III . Total fertility rate assumption during the projection period

\begin{tabular}{|l|c|c|c|}
\hline \multirow{2}{*}{ Projection period } & \multicolumn{3}{|c|}{ Total Fertility Rate } \\
\cline { 2 - 4 } & High variant & $\begin{array}{l}\text { Medium } \\
\text { variant }\end{array}$ & Low variant \\
\hline $1991-96$ & 2.0 & 2.0 & 2.0 \\
$1996-01$ & 2.0 & 2.0 & 1.9 \\
$2001-06$ & 2.0 & 1.9 & 1.8 \\
$2006-11$ & 2.0 & 1.9 & 1.7 \\
$2011-16$ & 2.0 & 1.8 & 1.6 \\
$2016-21$ & 2.0 & 1.8 & 1.6 \\
$2021-26$ & 2.0 & 1.8 & 1.6 \\
\hline
\end{tabular}

\subsection{Mortality Assumption}

The life expectancy at birth (average number of years lived by a new born baby if he/she follows the current age specific mortality patterns) is projected on the basis of the past experience of increase in the life expectancy at birth. A logistic growth function was fitted using trends in life expectancy at birth and it assumes that increase in life expectancy at birth follows an S-shaped curve. The logic behind using logistic growth function is that when the life expectancy at birth is very low, the increase is expected to be slow due to poor health facilities. Once the health facilities are provided and with improvement in socioeconomic conditions, the life expectancy increases at a faster rate. At the higher level of life expectancy, the rate of increase is slow and it would stabilise at the biological maximum. We assumed that the biological maximum is 80 years for males and 85 years for females. The survival rate for the projection period on the basis of the projected life expectancy at birth are derived from the west pattern of Coale and Demeny model life tables. 
Table IV. Projected life expectancy at birth

\begin{tabular}{|l|l|c|}
\hline \multirow{2}{*}{ Period } & \multicolumn{2}{|c|}{ Life expectancy at birth } \\
\cline { 2 - 3 } & Male & Female \\
\hline $1991-96$ & 71.13 & 76.48 \\
$1996-01$ & 72.91 & 78.38 \\
$2001-06$ & 74.37 & 79.90 \\
$2006-11$ & 75.54 & 81.08 \\
$2011-16$ & 76.48 & 82.00 \\
$2016-21$ & 77.23 & 82.71 \\
$2021-26$ & 77.82 & 83.25 \\
\hline
\end{tabular}

\subsection{Migration Assumption}

The migration assumption will not greatly influence the school age population due to selective migration in the adult ages. We assume that net migration (external and internal combined) from Kerala will be $-300,000$ (net loss) for every five-year during the projection period. This assumption was derived based on the recent estimates on migration given by Zachariah, 1998. According to his estimates, the net migration from Kerala, both external and internal combined, was $-744,000$ during the decade 1981-91. He has also observed that the net internal (within India) migration in the decade 1981-91 was less than that in the decade 197181 and he believes that out migration from Kerala to other states of India would decrease in the future. Therefore, we assume that net migration from Kerala within India would decrease in the future as well as the present volume of migration flow to other countries would continue. Taking this into account, we have assumed that net migration would be around $-153,000$ for males and $-147,000$ for females for every five-year, during the projection period. 


\subsection{Results of the Population Projections}

Table V shows the projected total population and school age population of Kerala under three variants up to the year 2026. Detailed tables covering population by age and sex for the projection period are given in the Appendix I. The population size of Kerala will increase from 29.1 million in 1991 to 40.7 million in 2026 under medium variant assumption. The annual growth rate would reach the maximum during the period 1996-2001 (1.36 per cent) and then start declining and will reach 0.6 per cent during 2021-2026, under the same assumption. The low and upper limits of the population size in 2026 would be 39.2 and 41.9 million respectively. The pie diagram in figure I show the percentage of population by broad age groups in Kerala for the base year and end year. The pie diagram shows that the percentage of old people in the population will increase from 5.8 per cent in 1991 to 13.8 per cent in 2021. The young age population would decline from 29.8 percent to 18.2 per cent whereas the share of working age population would increase between 1991 and 2021. The age pyramid in figure II shows the age structure of the population for the base year and end year. It illustrates that a dramatic change in the age structure of the population. Although young age population will be declining around 1 million between 1991 and 2026, there will be enormous pressure at the working age population (an increase of 9 million) and old age population (an increase of 4 million). 
Table V. Projected population in Kerala

\begin{tabular}{|c|c|c|c|c|c|c|}
\hline \multirow{2}{*}{ Year } & \multicolumn{2}{|c|}{ Total population (000) } & \multicolumn{3}{c|}{ School age (5-14) population (000) } \\
\cline { 2 - 7 } & Low & Medium & High & Low & Medium & High \\
\hline 1991 & 29100 & 29100 & 29100 & 5905 & 5905 & 5905 \\
1996 & 30904 & 30904 & 30904 & 5562 & 5562 & 5562 \\
2001 & 32931 & 33079 & 33079 & 5576 & 5576 & 5576 \\
2006 & 34711 & 35005 & 35151 & 5665 & 5813 & 5813 \\
2011 & 36166 & 36741 & 37026 & 5437 & 5730 & 5876 \\
2016 & 37328 & 38181 & 38740 & 5003 & 5429 & 5715 \\
2021 & 38362 & 39520 & 40360 & 4570 & 5129 & 5542 \\
2026 & 39208 & 40717 & 41870 & 4360 & 4945 & 5499 \\
\hline
\end{tabular}

Figure I. Percentage distribution of population by broad age group under medium variant for base and end year of projection, Kerala

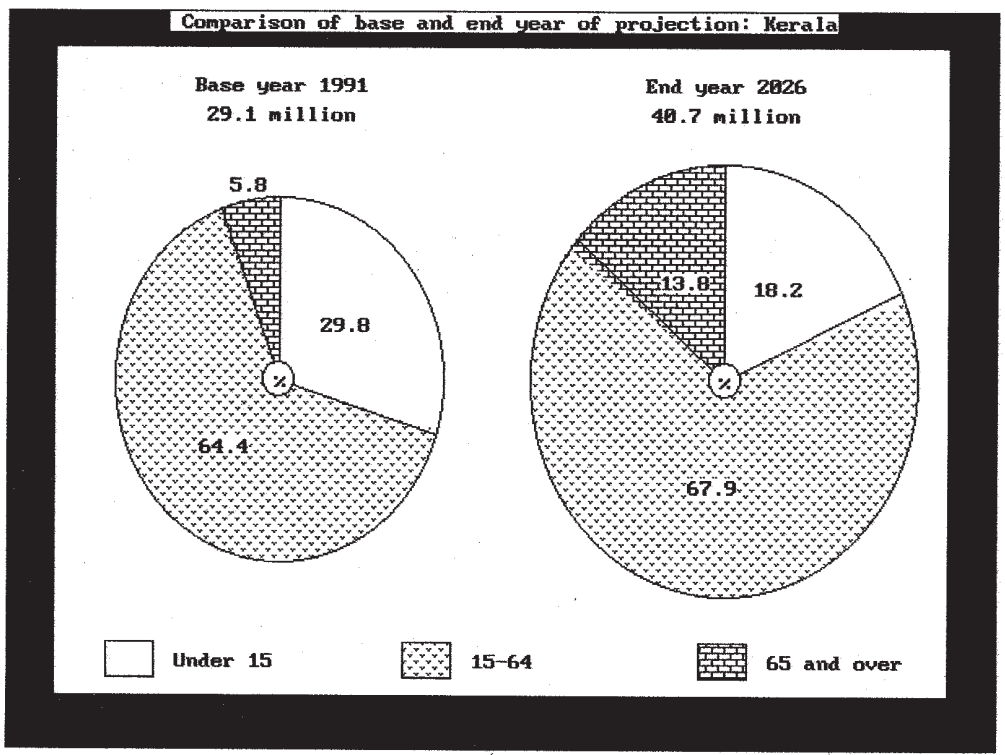


Figure II. Population age pyramids for base year and end year, (Medium Variant) Kerala

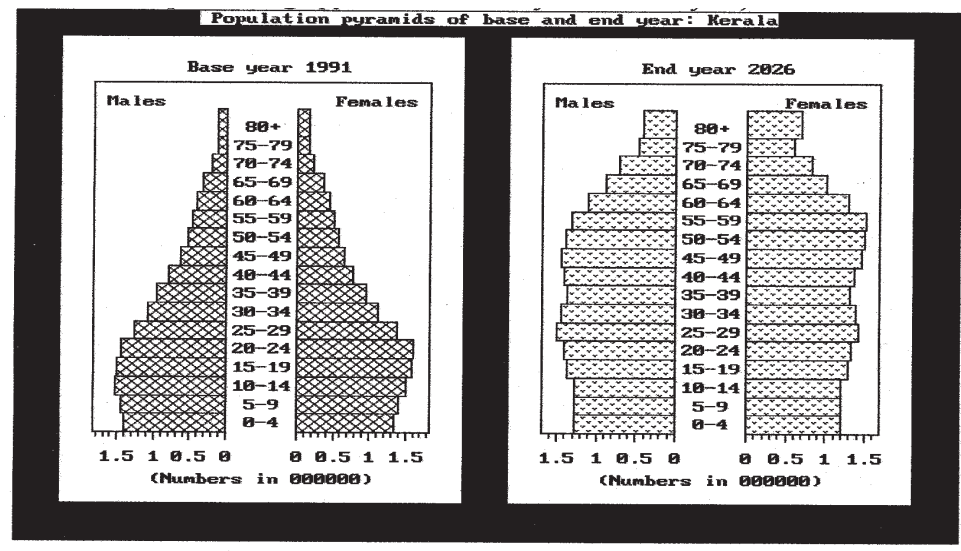

The school age population (5-14 years) declined from 59.72 lakhs in 1981 to 59.05 lakhs in 1991- a decline of 67000 during the decade 1981-91. What would be the future quantum of decline in the school age population in the next two decades? Table VI gives the projected school age population by single year age as well as by educational levels up to the year 2026. The school age population will decline from 59.05 lakhs in 1991 to 55.76 lakhs in 2001 and will increase to 58.03 lakhs in 2006 under the medium variant assumptions. This increase after the year 2001 is also true in the low variant projection. The school age population will reach 49.45 lakhs in the year 2026 under the medium variant assumption. Suppose all the school age population are enrolled in the school by 2026 (100 per cent enrolment rate), this will be equivalent to the number of students in the school in the year 1971-72 (49.36 lakhs). The school age population will decline from 59.05 lakhs in 1991 to 55.76 lakhs in 2001 and will increase to 56.65 lakhs in 2006 under low variant assumption. The increase in the school age population after 2001 is due to the effect of population momentum as more young women will be entering into the childbearing age (see figure II). Although fertility rate 
assumed to decline, the changing age structure of women will be responsible for the increase in the school age population after 2001. It should be noted that the changing age structure of women (more number of women in the reproductive ages) will be due to an increase in the survivorship of females from birth to reproductive ages, as well as the fact that these women would belong to the high fertility regime. In addition, more children will survive from birth to school age because of decline in the infant and child mortality rate.

\section{Figure III. Projected school age population (Medium Variant), Kerala}

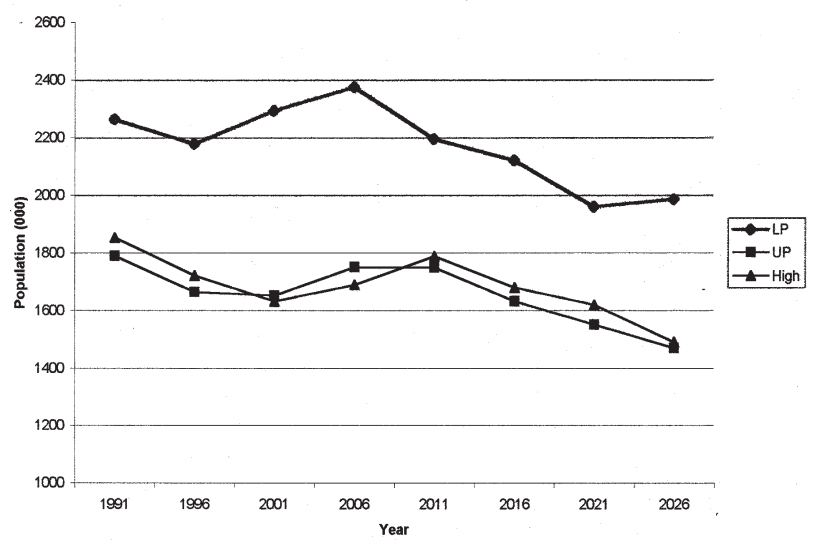

Figure III shows the trend in the school age population by educational levels, that is lower primary (5-8 age group), upper primary (9-11 age group) and high school (12-14 age group). The school age population in the LP level is expected to increase from 22.64 lakhs in 1991 to 23.76 lakhs in 2006 and decline to 19.87 lakhs in 2026. It declines upto 2001 and thereafter it shows an increasing trend until 2006. In the case of UP level, the school age population will decline from 17.89 lakhs in 1991 to 16.51 lakhs in 2001 and will increase to 17.48 lakhs before it starts declining. The school age population in the high school level declines till 2001 and then increases till 2011. 
Table VI. Projected school age population by single year age, Kerala ( in 000')

\begin{tabular}{|c|c|c|c|c|c|c|c|c|}
\hline Age & 1991 & 1996 & 2001 & 2006 & 2011 & 2016 & 2021 & 2026 \\
\hline & 556 & 546 & 578 & 553 & 505 & 458 & 429 & 435 \\
\hline & 562 & 544 & 576 & 560 & 515 & 467 & 432 & 435 \\
\hline & 569 & 544 & 571 & 565 & 525 & 476 & 436 & 435 \\
\hline & 578 & 546 & 566 & 569 & 534 & 486 & 442 & 434 \\
\hline . & 587 & 549 & 560 & 571 & 543 & 495 & 449 & 434 \\
\hline 1 & 596 & 554 & 552 & 573 & 551 & 505 & 458 & 433 \\
\hline 1 & 606 & 560 & 544 & 575 & 559 & 515 & 467 & 432 \\
\hline 1 & 614 & 566 & 540 & 573 & 565 & 524 & 476 & 434 \\
\hline 1 & 618 & 573 & 542 & 568 & 569 & 534 & 486 & 440 \\
\hline 1 & 620 & 581 & 548 & 560 & 571 & 543 & 495 & 449 \\
\hline L.P & 2264 & 2179 & 2291 & 2246 & 2079 & 1887 & 1739 & 1739 \\
\hline U.P & 1789 & 1663 & 1656 & 1719 & 1653 & 1515 & 1374 & 1299 \\
\hline High & 1852 & 1720 & 1629 & 1701 & 1705 & 1600 & 1457 & 1322 \\
\hline Total & 5905 & 5562 & 5576 & 5665 & 5437 & 5003 & 4570 & 4360 \\
\hline
\end{tabular}

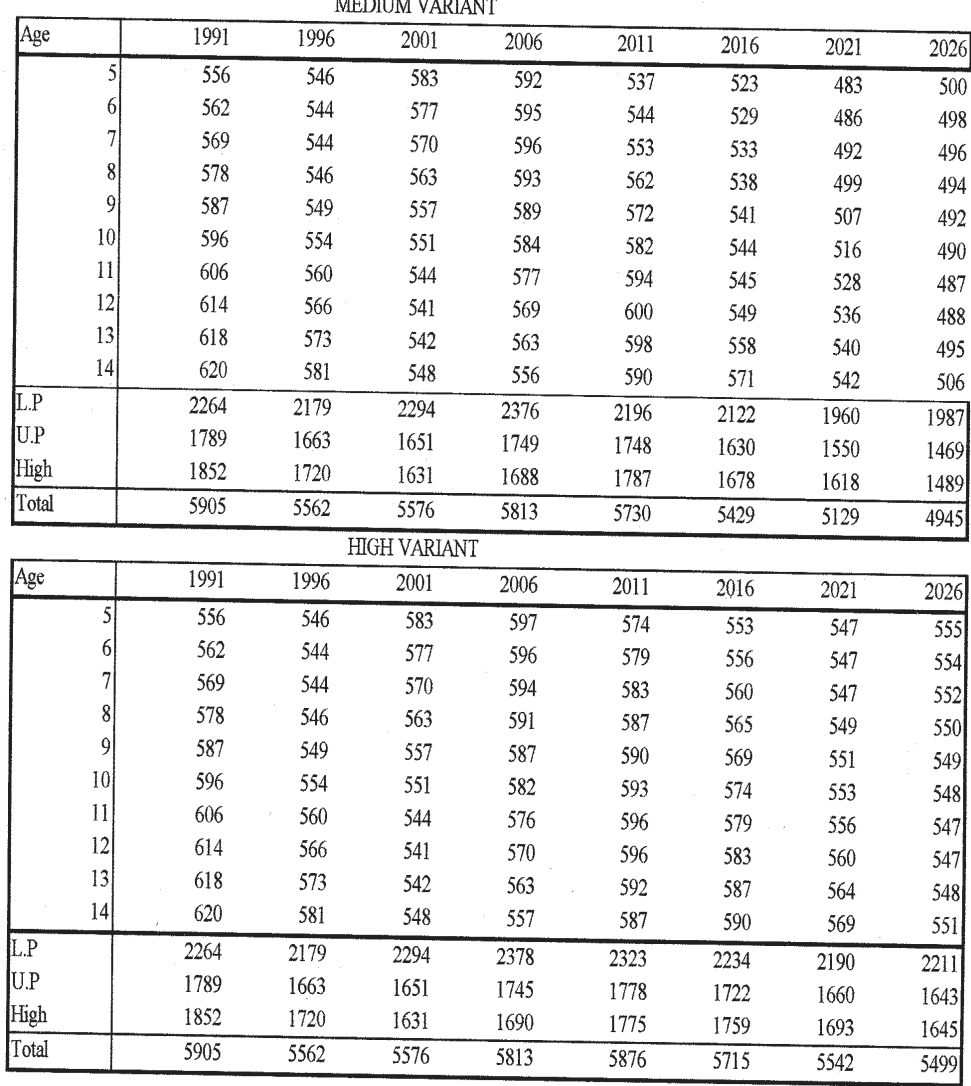




\section{Implications for Educational Planning}

In the population projections presented in the preceding section, a decline from less than one lakh to 4.68 lakhs is expected in the school going age population between 1991 and 2011 under various fertility assumptions. But it also shows that at the LP level there will be an increase in school going age population from 1996 to 2006. In UP and High school level there will also be an increase from 2001 to 2011 with gap of 5 years from LP level age group. These aggregate projections itself indicates that any expansion of the school system, should be done only with careful planning. With regard to the planning of new primary schools, the Fifth All India Educational Survey (FAIS)[1992] has indicated how it is to be done [p.40] :

" [This was done] either by proposing an independent primary school to a habitation with a population of 300 or more without any schooling facilities within one kilometre radius or clubbing together a cluster of habitations within one kilometre radius with a population of 300 or more and proposing a new school. Population and distance criteria have been relaxed in the case of topographically difficult regions."

The findings of the survey indicate that 695 primary schools have to be newly established in Kerala under the criteria quoted above. Similarly, 259 upper primary schools are also proposed for Kerala [p.1284-5]. Further, this State has its share of schools without basic equipment like black boards and furniture [see Table VII] and ancillary facilities for drinking water, latrine and for medical check up and vaccination [see Table VIII]; though proportionately much less than for all India. 
Table VII. Availability of black boards, furniture and mats in the schools in Kerala and India, 1992.

\begin{tabular}{|l|r|r|r|r|}
\hline \multirow{2}{*}{ Facilities } & \multicolumn{2}{|c|}{ Kerala } & \multicolumn{2}{c|}{ India } \\
\cline { 2 - 5 } & Number & Percent & Number & Percent \\
\hline No. of schools & 6096 & - & 528730 & - \\
\hline No. of Sections & 51199 & 100 & 2658220 & 100 \\
\hline No. of sections having & & & & \\
(i). Usable Black board & 46987 & 91.8 & 472823 & 17.8 \\
(ii). Unusable black board & 2447 & 4.8 & 1162050 & 43.7 \\
(iii). No black board & 1762 & 3.4 & 1023347 & 38.5 \\
\hline No. of sections with furniture & & & & \\
(i). Chair and Table & 40740 & 79.6 & 1053202 & 39.6 \\
(ii). Chair only & 3885 & 7.6 & 461154 & 17.3 \\
(iii). Table only & 4033 & 7.9 & 129150 & 4.9 \\
(iv). Neither chair nor table & 2541 & 3.0 & 1014714 & 38.2 \\
\hline No. of sections having & & & & \\
(i). Mats & 41439 & 80.9 & 924944 & 34.8 \\
(ii) Inadequate mats & 7836 & 15.3 & 381806 & 14.4 \\
(iii). No mats & 1924 & 3.8 & 1351470 & 50.8 \\
\hline
\end{tabular}

Source: NIEPA(1992).

Table VIII. Availability of ancillary facilities in schools, Kerala and India, 1992

\begin{tabular}{|l|r|r|r|r|}
\hline \multirow{2}{*}{ Facilities } & \multicolumn{2}{|c|}{ Kerala } & \multicolumn{2}{c|}{ India } \\
\cline { 2 - 5 } & Number & Percent & Number & Percent \\
\hline No. of schools & 6096 & 100 & 528730 & 100 \\
\hline Drinking water & 4658 & 76.4 & 250369 & 47.4 \\
Urinal & 3962 & 65.0 & 81929 & 15.5 \\
Separate urinal for girls & 1750 & 28.7 & 27232 & 5.2 \\
Lavatory & 1517 & 24.9 & 33197 & 6.3 \\
Separate lavatory for girls & 438 & 7.2 & 14584 & 2.8 \\
Medical check-up & 2950 & 48.4 & 139449 & 26.4 \\
Vaccination & 2325 & 38.1 & 180291 & 34.1 \\
\hline
\end{tabular}

Source: NIEPA (1992) 
This means even in Kerala, a State with total literacy and high enrolment rates etc, expansion of primary and upper primary schools and school facilities are still needed. One way of locating exactly where such expansion is to be effected, is by projecting population at the district and taluk levels. As mentioned earlier, our State level projection itself shows decline in the school age population of around 1.75 lakhs between 1991 and 2001 in the medium variant projection. This is most likely be accounted by decline in the growth of school age populations of those districts which have relatively high fertility levels. These districts are also districts with less literacy levels like Malappuram, Wayanad, Kasaragode and Palakkad compared to the State as a whole [See Table IX]. Further all these four districts have higher students per school, compared to State average, leading to a disparity in the number of schools in the district, relative to the number of students [See Table X]. For example, 32.38 per cent of the L.P students of the State and who come from these districts are studying in 26.24 per cent of the total L.P schools available in the state. In the case of U.P section, this percentage is 25.61 percent of the students studying in 12.61 per cent of the U.P schools in these districts. Similarly, 20.5 per cent of high school students of the state in these four districts are studying in 7.64 per cent of the total high schools in the state available in these districts. Therefore, further analysis on the basis of population projections and capacity to accommodate students in schools, to plan for the educational sector of these districts are necessary. 
Table IX. Crude birth rate and effective literacy rate by districts in Kerala

\begin{tabular}{|l|c|l|l|l|}
\hline \multirow{2}{*}{ State/District } & Crude birth rate & \multicolumn{3}{|l|}{ Effective Literacy Rate, 1991(\%) } \\
\cline { 3 - 5 } & $1984-90$ & Male & Female & Total \\
\hline Malappuram & 29.5 & 92.08 & 84.09 & 87.94 \\
Kasaragode & 24.4 & 88.97 & 76.29 & 82.51 \\
Wayanad & 23.4 & 87.59 & 77.69 & 82.73 \\
Palakkad & 22.5 & 87.24 & 75.72 & 81.27 \\
Kannur & 20.5 & 95.54 & 87.65 & 91.48 \\
Kozhikode & 20.5 & 95.58 & 86.79 & 91.10 \\
Idukki & 19.8 & 90.82 & 82.96 & 86.94 \\
Thiruvananthapuram & 19.6 & 92.84 & 85.76 & 89.22 \\
Thrissur & 18.7 & 93.77 & 86.94 & 90.10 \\
Kollam & 18.5 & 94.09 & 87.00 & 90.47 \\
Pathanamthitta & 17.2 & 96.55 & 93.29 & 94.86 \\
Ernakulam & 16.9 & 94.46 & 89.27 & 92.35 \\
Alappuzha & 16.7 & 96.79 & 91.12 & 93.87 \\
Kottayam & 16.6 & 97.46 & 94.00 & 95.72 \\
\hline Kerala & 20.3 & 93.62 & 86.17 & 89.81 \\
\hline
\end{tabular}

Source: Bhat, P.N.M. (1996) and Census of India, Kerala, 1991.

While it is evident that the lower birth rate in Kerala will have an over all impact on school enrolment with a time lag; there are other factors to be taken into account. On the one hand the comparatively educationally forward districts like Kottayam, Ernakulam and Alappuzha and which are also lower birth rate districts, are likely to be closer to the lowest limit and not much further decline is to be expected there. On the other hand the higher birth rate districts which are mostly higher illiteracy rate districts can be expected to have a decline in birth rate, and therefore, the overall decline in the school age population in Kerala will be mostly 
accounted by these districts. Also, these districts viz., the so far educationally backward districts, can also be expected to act differently with regard to enrolment in higher classes. These districts can be expected to enrol higher number of students in higher classes resulting in increase in the enrolment rate at the high school level, as the educationally forward districts are already doing. In other words, the drop out rates in schools in the currently educationally backward districts are likely to decrease or get transferred to still higher classes. Therefore, increase in the enrolment rate at the high school level will be on an increase till 2026 and would not be less than the number of students currently enrolled at the high school level.

The annual average standard progression ratio $^{6}$ for all Kerala, for both males and females shows a steady increase over the years 1960 to 1981 [see Table XI]. Particularly impressive is the greater increase in the case of female progression ratios. This data is available for only upto 1981. Further they are State level aggregates. There are other substantiating data at the district level too. In growth of student population by various levels of education, it is found that Malappuram registers highest rate of growth with regard to the high school sections [Graph I]. The same trend is seen in the case of Palakkad [Graph II] and Idukki [Graph III] two other educationally backward districts.

6 Standard progression ratio is defined as the proportion of students passing to another standard (class) given that one has already completed certain standard (class). While computing we have assumed no repeaters in any class or standard and therefore it is a crude measure. 


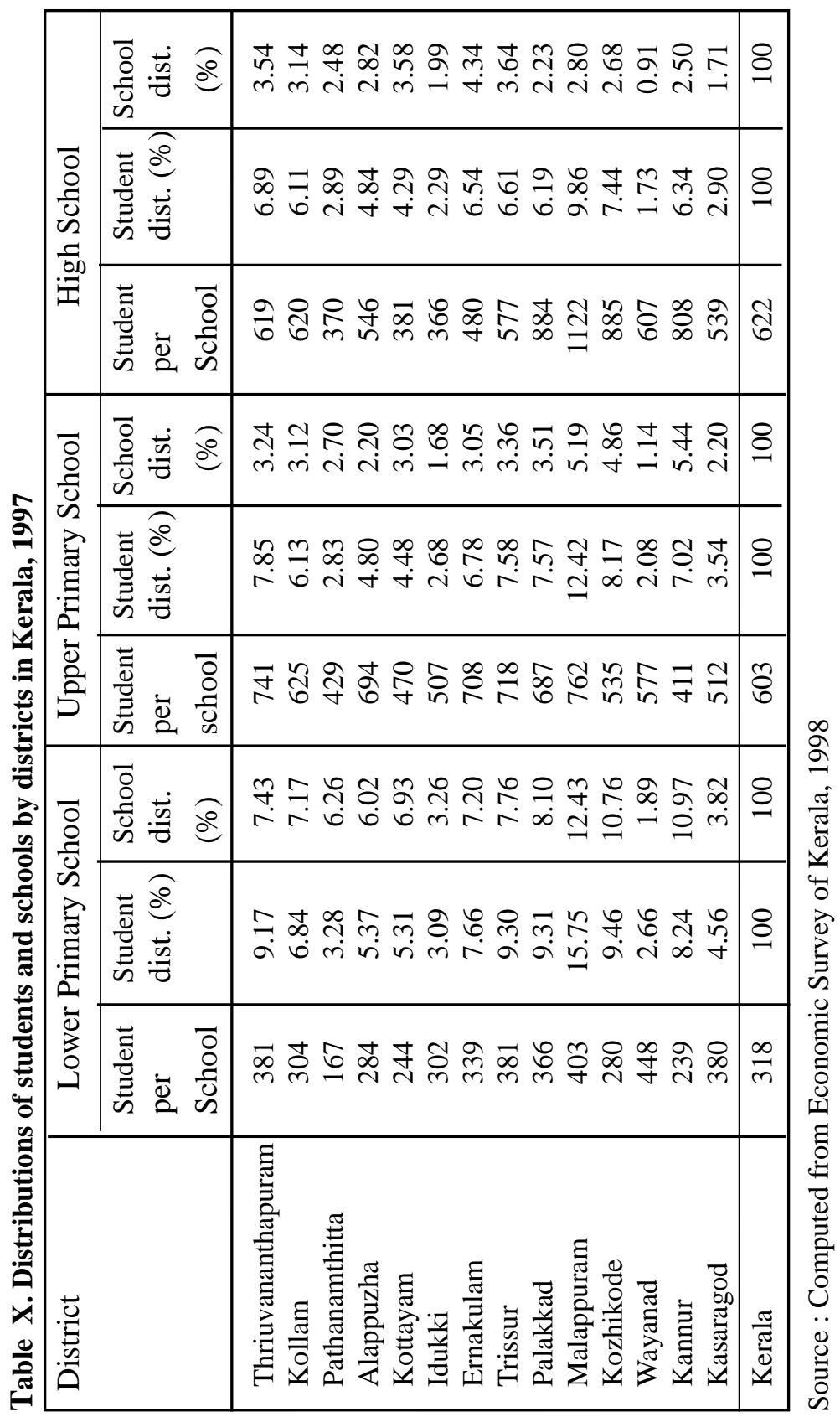




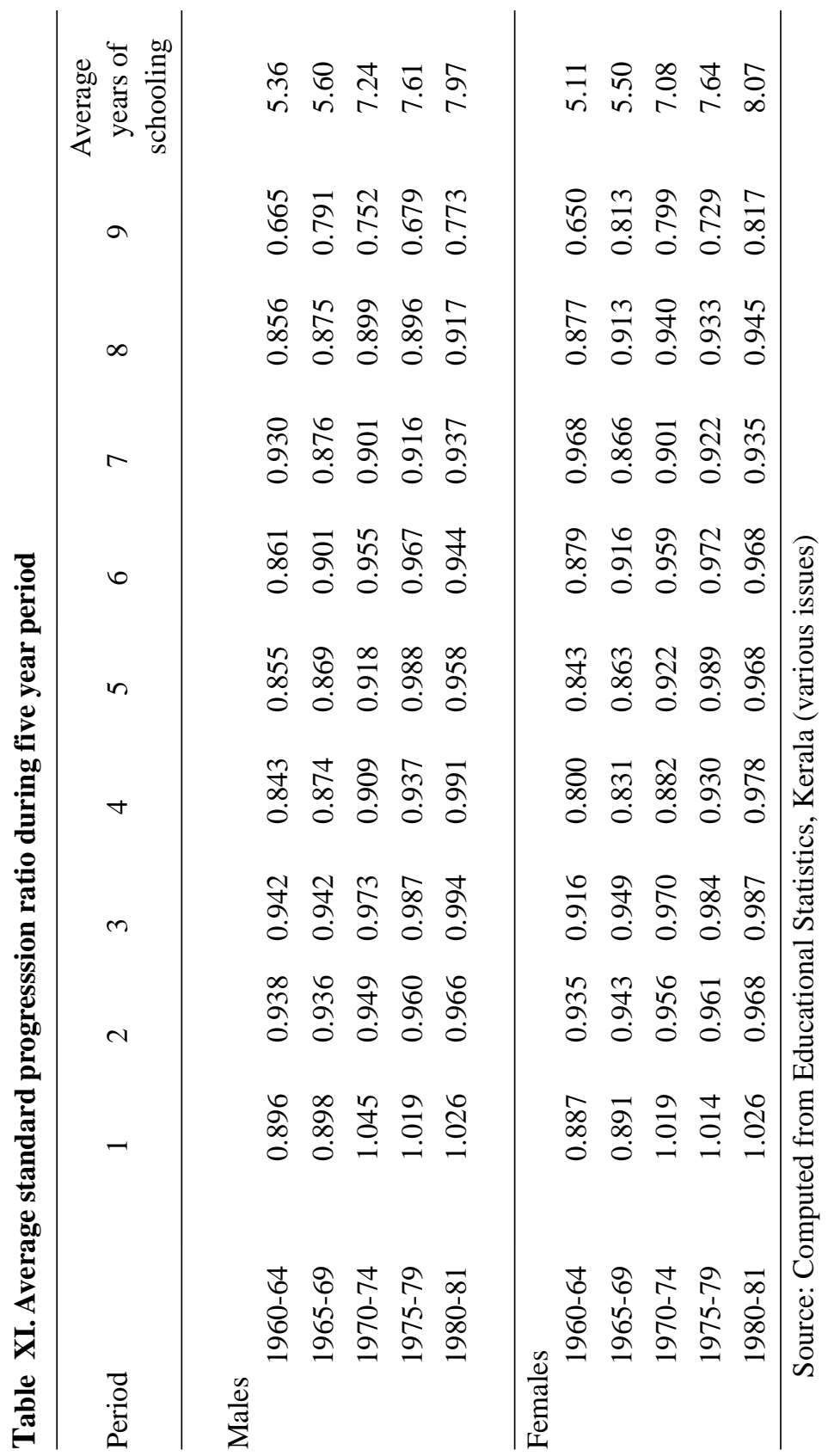



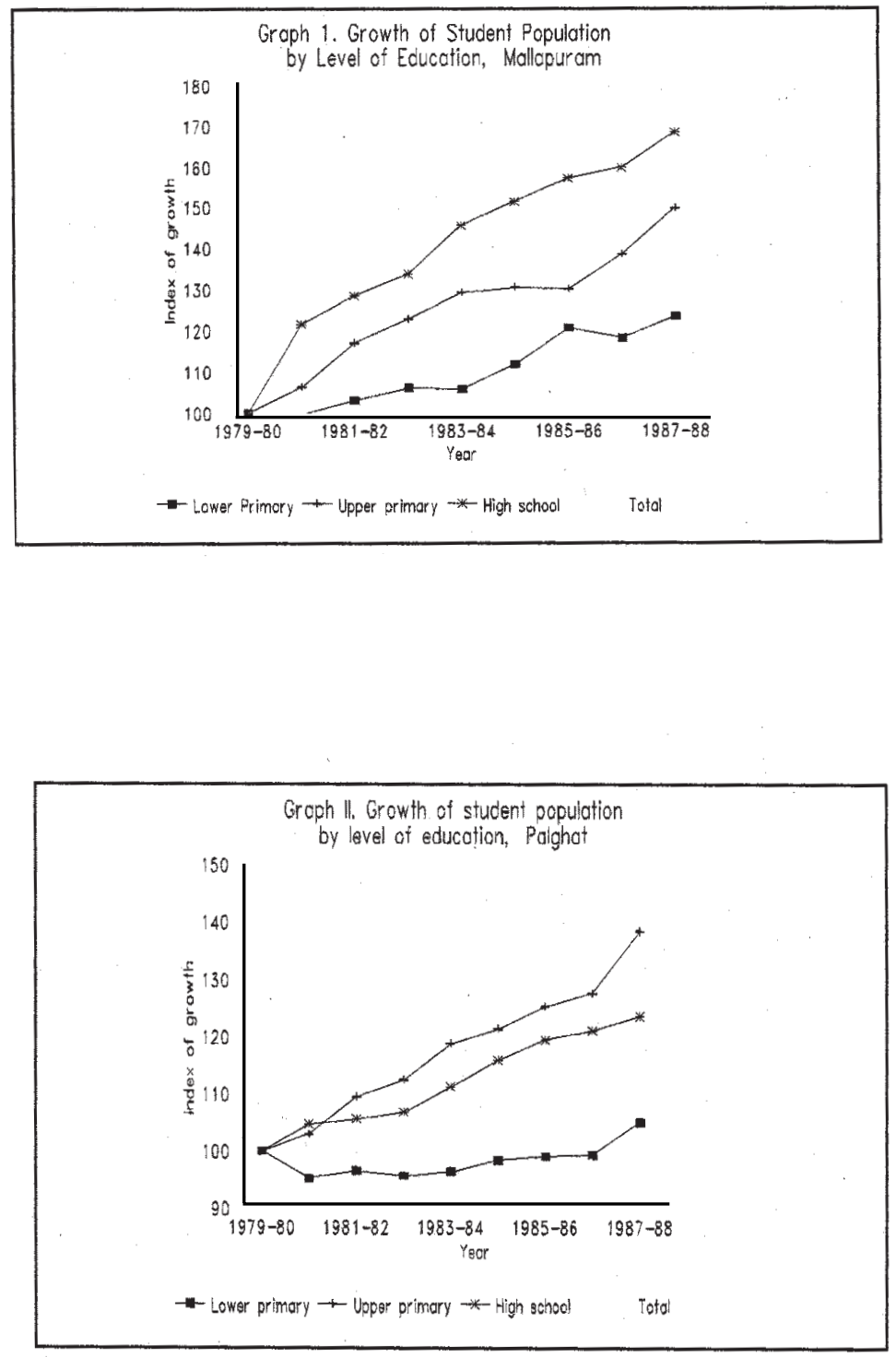


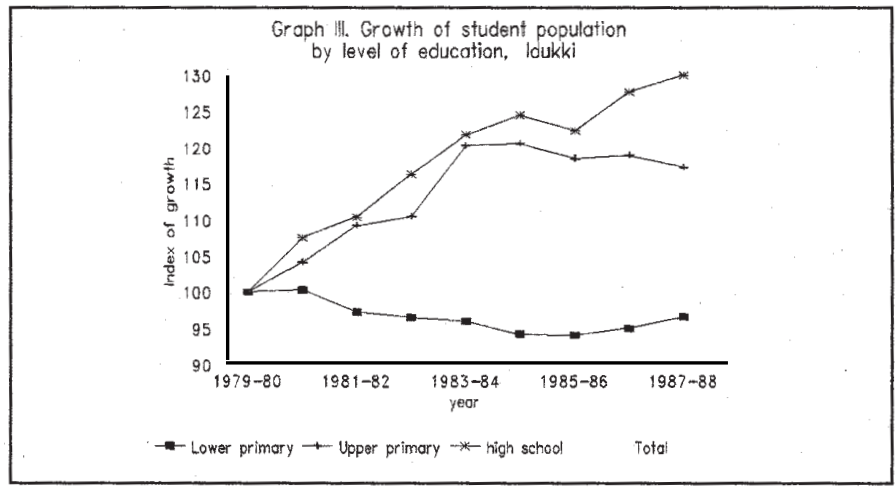

This kind of behaviour is expected. If a lower birth rate is preferred, it means that child's services are not immediately needed in the household. In a region which is going through the process of lowering birth rate, the next most desired occupation (if the child services are not required for household work) is for schooling. If other factors are the same, the children in a region of such characteristics are likely to spend more years in school. This will have implications for the labour market. But we will not go into that. We will restrict the discussion to the implications for both built-up educational facilities and for further investments for building up additional facilities. One distinct implication that can be drawn from such observations is that school buildings and other accessory facilities are not to be built up any more in some districts; unless some special case is found to be existing. This seems to be the case for almost all Kerala; if the requirements for special regions and groups that are reflected in the FAIES [p.1280-81] are taken care of. But our own population projections in the high variant showed that after a decline of school going age population between 1991 and 2001, there will be an increase over the next 10 years. Further, even on the medium variant assumption, after a decline in school going age population between 1991 
and 2001 there will be an increase between 2001 and 2006 and will decline only thereafter.

Since educational facilities like schools and their accessories are built up over the long term, their availability cannot be easily changed according to changes in population from time to time. The already available facilities should be used for future requirements and in the short term, used for alternative purposes. The alternative uses of elementary educational facilities should be within elementary educational sector itself. This is because primary/elementary education is a priority sector. In the case of all India, B.S. Minhas (1991) after analysing the National Sample Survey's [NSS] enquiry on the patterns of access to social services, came to the conclusion that the poorest 40 to 50 per cent of the households seem hopelessly unable to spare their 6 to 14 year olds from household's economic activity, domestic chores and other economic pressures to avail even of free education. He further argued that these demand -side constraints on participation in education by the poor are further reinforced from the supply side inadequacies of the educational sector. According to him, the available educational facilities are of abysmally low quality, which breeds indifference and disinterestedness among the poor children. In the case of Kerala, even the poorer households can be expected to behave differently, since education is held to be of high premium here. Notwithstanding that, as a further incentive for advancing basic education, [in the context of EFA], the quality of education, both by teaching -learning components and by physical facilities for education have to be upgraded. The alternative uses for which the built-up educational facilities can be utilized, in this context, could be for up-gradation of physical factors in the educational sector. As far as the schools to be closed down in Kerala are concerned, there apparently is no such move to use them for any alternative 
educational use in the primary education sector itself ${ }^{7}$. On the other hand there are several stories reported of severe neglect of even well run public schools. The up-gradation of even other factors contributing to quality of learning at the school level is an inevitable requirement in Kerala is substantiated by the fact that the Kerala Sasthra Sahithya Parishath [KSSP] in an extended sample survey have estimated that as high as over 30 per cent of students in classes upto the seventh standard do not have the language skills expected of fourth standard students.

There are special problems pertaining to social groups which are educationally backward. The traditional fisher-folk particularly of Thiruvananthapuram and Malappuram Districts had the level of literacy as 39 per cent and 35 per cent in 1979. In the nearest population census of 1981 the general population in these districts had literacy levels of 71 per cent and 60 percent respectively [Table XII]. Also, the literacy levels of SC and ST population is significantly lower than the non-SC/ ST population as per the 1991 census in all the districts in Kerala [Table XIII]. Muslim community, particularly Muslim women, Tribal population, and a small caste called Kudumbis [Schenk- Sandberger, 1989] are all backward in basic literacy. It is evident that schools catering

7 Earlier, there was one newspaper report that the Nandavanam L.P.School in Thiruvananthapuram was used to pack and sort out kits of vegetable seeds, to be distributed by the department of Agriculture. The State Horticultural Corporation which sought the assistance of school students for this purpose used the closed school building for that purpose [Malayala Manorama, 16 June, Thursday, 1992). In Chengannur, the closed school was used to start self-financing college [Malayala Manorama, 17 February, Thursday, 1994] Apart from the controversy surrounding the self-financing colleges, it is doubtful whether convertion of school buildings into colleges, (unless they can be specifically proven to be warranted) is the best use of basic or elementary education facilities. 
predominantly to these communities cannot be just closed on the basis of general population projections. This is reflected in the reported concern shown by the three member committee headed by the DPI for fisheries and tribal schools as mentioned earlier [see foot note no. 2]. Such schools are likely to require better attention and internal and external reorganization to make them more effective in serving the cause of education of these educationally backward communities.

Table XII: District-wise distribution of the literacy rate of the total population and fishing population

\begin{tabular}{|l|c|c|}
\hline \multirow{2}{*}{ Districts } & \multicolumn{2}{|c|}{ Literacy Rate (percent) } \\
\cline { 2 - 3 } & $\begin{array}{c}\text { Total Population } \\
(1981)\end{array}$ & $\begin{array}{c}\text { Fishing Population } \\
(1979)\end{array}$ \\
\hline Thiruvananthapuram & 71 & 39 \\
Kollam & 74 & 68 \\
Alappuzha & 79 & 72 \\
Ernakulam & 77 & 80 \\
Thrissur & 74 & 66 \\
Malappuram & 61 & 35 \\
Kozhikode & 70 & 67 \\
Kannur & 66 & 65 \\
\hline Kerala & 70 & 62 \\
\hline
\end{tabular}

Source : Thomas, J. 1989, p. 19. 
Table XIII. Disparity of literacy levels among caste groups in Kerala, 1991

\begin{tabular}{|c|c|c|c|c|c|c|c|c|c|}
\hline \multirow{3}{*}{ District } & \multicolumn{9}{|c|}{ Effective literacy rate (\%) } \\
\hline & \multicolumn{3}{|c|}{ NON-SC/ST } & \multicolumn{3}{|c|}{$\mathrm{SC}$} & \multicolumn{3}{|c|}{ ST } \\
\hline & Total & Male & Female & Total & Male & Female & T otal & Male & Female \\
\hline Kasargod & 85 & 91 & 78 & 64 & 70 & 57 & 66 & 75 & 58 \\
\hline Kannur & 92 & 96 & 88 & 85 & 90 & 80 & 59 & 65 & 52 \\
\hline Wayanad & 90 & 94 & 86 & 75 & 82 & 69 & 51 & 58 & 43 \\
\hline Kozhikode & 92 & 96 & 87 & 86 & 91 & 81 & 52 & 57 & 48 \\
\hline Malappuram & 89 & 93 & 85 & 79 & 85 & 74 & 44 & 50 & 38 \\
\hline Pallakkad & 85 & 91 & 80 & 67 & 75 & 60 & 35 & 40 & 29 \\
\hline Thrissur & 92 & 95 & 89 & 79 & 84 & 74 & 51 & 55 & 48 \\
\hline Ernakulam & 93 & 96 & 90 & 82 & 87 & 78 & 77 & 81 & 72 \\
\hline Idukki & 91 & 94 & 88 & 73 & 81 & 64 & 63 & 68 & 57 \\
\hline Kottayam & 96 & 98 & 95 & 90 & 94 & 87 & 89 & 90 & 87 \\
\hline Alappuzha & 94 & 97 & 92 & 89 & 94 & 85 & 74 & 80 & 69 \\
\hline Pathamthitta & 96 & 98 & 95 & 86 & 90 & 83 & 73 & 76 & 71 \\
\hline Kollam & 90 & 94 & 87 & 82 & 87 & 78 & 74 & 82 & 67 \\
\hline Thiruvananthapuram & 90 & 94 & 87 & 82 & 87 & 78 & 74 & 82 & 67 \\
\hline Kerala & 91 & 95 & 88 & 80 & 85 & 74 & 57 & 63 & 51 \\
\hline
\end{tabular}

Source: Census of India, 1991.

If alternatives are to be suggested taking into account the educational requirements of backward districts and groups, it has to be within the context of a comprehensive scheme of development of primary education. Such a scheme is not attempted here. Nevertheless, some tentative requirements, in terms of qualitative physical improvement and in terms of eventual upgradation of schooling, can be discussed. The primary asset acquired over the years of educational investment is builtup space. Unless the school buildings are so dilapidated that they have to be scrapped; they should be made use of for alternative educational 
purposes. School buildings can be used for, educational stores, laboratories, libraries, summer camps, child health programmes, literacy classes and learning parks etc. Buildings as well as grounds can also be utilized for development of sports and games. Several such alternative uses for built-up educational space can be thought of within the requirements of educational up-gradation.

Evidently, such rationalization and reorganization has to be done with proper planning. More importantly, the authority to implement such plans should be vested in the hands of a public body. As far as the government schools are concerned, already the DPI has such authority. But in the case of individual private schools, [inspite of considerable leverage that DPI has in lieu of grants for maintenance and staff salary] such authority is constrained by a variety of contractual agreements ${ }^{8}$. In such circumstances, legal and legislative measures may be required to facilitate implementations of the afore-mentioned projects by the DPI, or still better, by local authorities like the District or Village Panchayats. Such requirements have direct policy implications.

\section{Summary and Conclusion}

Decelerating birth rate and its expected impact upon primary school enrolment, by itself cannot be considered as cause enough to withdraw public investment in school education sector. First of all, such over all change will hide within it level-wise changes of demand for education; from lower to higher school classes as it was seen in the case of relatively 'backward' districts. In addition, the overall change itself is not to be so

8 Private managers of schools in city area tend to close down schools in the context of increasing land prices. Though the government can take over such schools and run them for five years, the government will have to give high rents. To prevent this new legislation is required [Malayala Manorama, 3 April, Sunday, 1994]. But it should be remembered that the schools already closed or are identified to be closed includes private (aided) as well as public schools. 
high. Among the three assumptions, the medium variant shows that the fall will be around 3.29 lakhs between 1991 and 2001. However, there will be an increase in the school age population of around 2.37 lakhs between 2001 and 2006 and 1.54 lakhs between 2001 and 2011 . Therefore, the fruits of fertility decline will be realized fully after the year 2011 in the school age population. In that context, if built up school space is allotted for uses outside schooling purposes, it will not be a good policy, particularly in a situation where much more investment into qualitative improvement of schooling is called for. The argument that the closed schools can be better made use of by allotting them for self- financing colleges cannot be an adequate policy response. Such a shift of investment of built up space away from primary to higher education sector will be against all principles of equitable education.

In these circumstances, the decelerating birth rate should be carefully monitored and taking into account its trend and location further investment should be reoriented and rationalized. States like Kerala which have already made impressive gains in mass education can have reversals if the intricacies in changing demand for education is not anticipated and provided for. More investments for building up higher classes, wherever required, and extension of accessory services to qualitative improvement of school education, are needed. These needs are much more important with regard to backward groups and regions. To maintain public investment for school education, new innovative organizational and resources - saving as well as sharing methods like, PTAs, decentralized management and community support can be utilized. To close schools purely on the basis of decelerating demographic trends will be counterproductive to the nationally and internationally accepted target of education for all. 


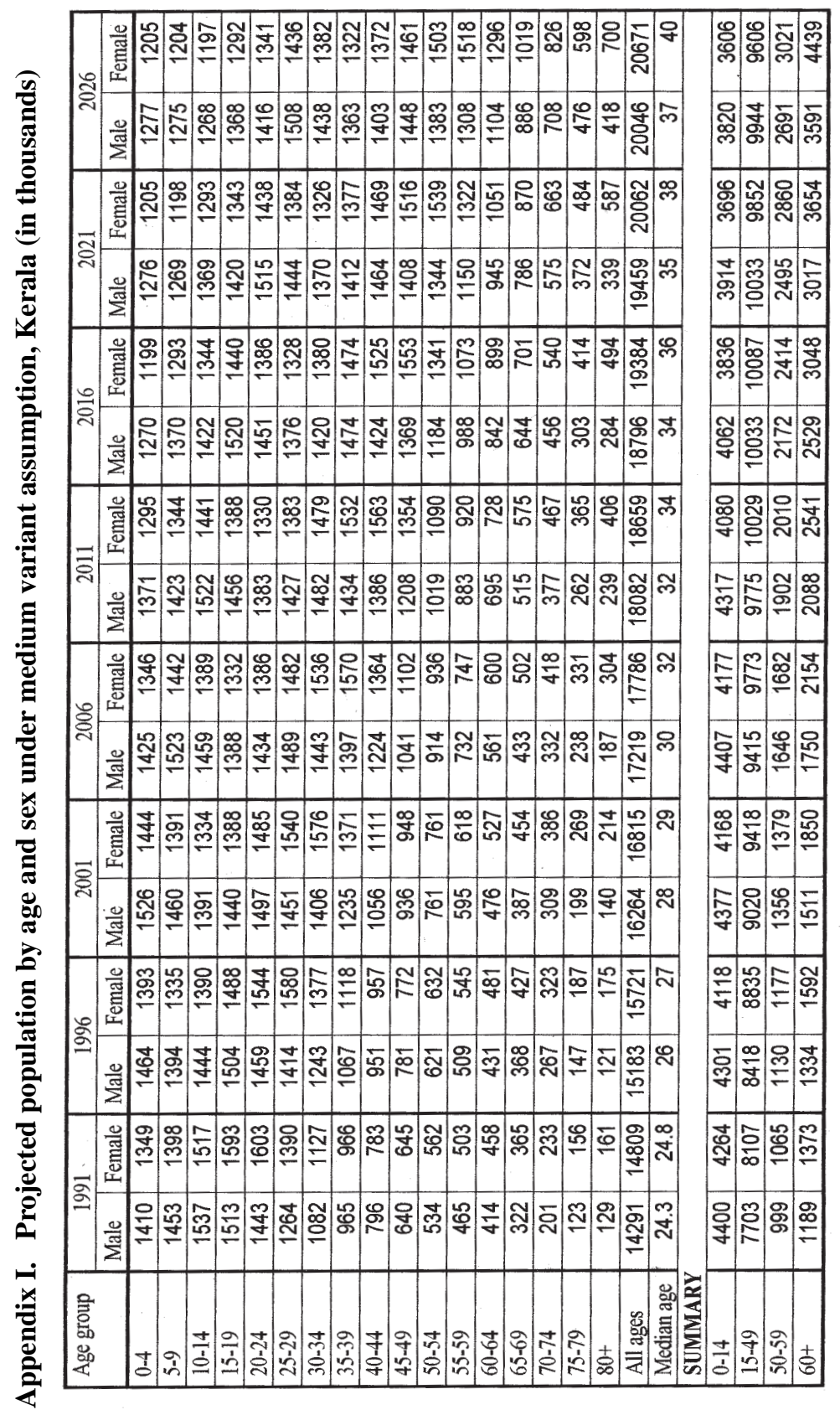




\section{REFERENCES}

Ahlburg, D.A and J.W. Vaupel (1990). "Alternative Projections of the U.S. Population”, Demography, Vol. 27, No.4, pp.639-652.

Bhat, P.N.M. and Rajan, S.I (1991). "Demographic Transition in Kerala Revisited", Economic and Political Weekly, sep 1-8, pp 19571980.

Bhat, P.N.M. (1996). Contours of Fertility Decline in India: A District Level Study Based on the 1991 Census, Discussion Paper Series No. 13., Studies on Human Development in India, UNDP Research Project, Centre for Development Studies, Trivandrum.

Bongaarts, J and G. Feeney (1998). "On the Quantum and Tempo of Fertility", Population and Development Review, Vol. 24, No.2. pp 271-291.

Census of India, 1971. Social and Cultural Tables, Series 9, Kerala, Part II - c(ii) (c-i to c-vi and F-i to F-v).

Census of India, 1981. Social and Cultural Tables, Series 10, Kerala, Part IV-A.

Census of India, 1981. Final Population Totals, Paper 3 of 1981, series 10, Kerala, Directorate of Census Operation, Trivandrum, Kerala.

Census of India, 1991. Provisional Population Total, Kerala, Series 12, Paper 1 of 1991, Directorate of Census Operation, Kerala.

Chari, R.B (1977). Age tables, Census of India, 1971, Series 1 Paper 3 , Office of the Registrar General India, New Delhi.

Coale A.J. and P. Demeny (1983). Regional Model Life Tables and Stable Population, Second Edition. Academic Press, New York.

Devassy, M.K. (1965). General Report, Kerala, Census of India, 1961, Vol VII, part IA (i). 
Directorate of Public Instruction. (1987). Educational Statistics, 1987, Dept. of Education, Government of Kerala, Trivandrum.

Dreze, J. and Saran M. (1993). Primary Education and Economic Development in China and India: Overview and Two Case Studies, Development Economic Research Programme, London School of Economics, London, DEP 47.

Frontline (1992). “A bitter lesson, Targeting 'uneconomic' schools in Kerala” [Bhasker, B], November 6, pp. 88-92

George, K.K. (1993). Limits to Kerala Model of Development, Monograph Series, Centre for Development Studies, Thiruvanathapuram.

Gopinathan Nair, P.R (1987). Incidence, Impact and Implications of Migration: Emigration to Middle East from Kerala (India).

Government of India (1989). Family Welfare Programme in India, Year Book, 1988-89, Ministry of Health and Family Welfare, Dept. of Family Welfare.

Government of India, (1993). Education for All, The Indian Scene (second edition), Ministry of Human Resource Development, Department of Education, New Delhi.

Hajnal, J. 1947. "The Analysis of Birth Statistics in the Light of the Recent International Recovery of the Birth Rate", Population Studies, 1: 137-164. Cited in Bongaarts and Feeney (1998).

Nair, P.S. et al. (1994). National Family Health Survey 1992-93, Population Research Centre, University of Kerala, Trivandrum and International Institute for Population Sciences, Bombay.

Jalaluddin, A.K. (1991). Basic Education and National Development, The Indian Scene, UNICEF Sponsored Research Study under the Project Basic Education and National Development: Lessons from China and India, [Revised Draft], Delhi, University of Delhi. 
Kerala, Government of (1988). Report of the Survey on the Utilization of Gulf Remittances in Kerala, Department of Economics and Statistics, Trivandrum, December, 1987

Kumar, R.S. (1993). "Participative Management in Schools, Education", The Hindu, 5 October 1993.

Mathew. A. (1987). A History of Educational Development in Kerala, (Mimeo), National Institute of Educational Planning and Administration, New Delhi.

Minhas, B.S. (1991). Educational Deprivation and its Role As a Spoiler of Access to Better Life in India, Technical Report No. 9104. Indian Statistical Institute, New Delhi.

MOHRD (1994). Budgetary Resources for Education, Ministry of Human Resources Development, Govt. of India.

Nair, P.R. Gopinathan (1983). Educational Reforms in India: Universalisation of Elementary Education, Working Paper No. 181, Centre for Development Studies, Trivandrum.

Nair, P.R. Gopinathan (1977), “Education and Socio-Economic Change in Kerala, 1793-1947”, Social Scientist, Vol 4, No.8, March 1976, pp.28-43.

Nair, P.R. Gopinathan (1981), Primary Education, Population Growth and Socio-Economic Change: A Comparative Study with Particular Reference to Kerala, Allied Publishers Pvt Ltd, New Delhi.

Groenewold G. and Navaneetham, K. The Projection of Populations: Data Appraisal, Basic Methods and Applications, Population and Development Teaching Text, Centre for Development Studies, Thiruvananthapuram.

NIEPA, (1992). Fifth All India Educational Survey, Vol II, NIEPA, New Delhi. 
Office of the Registrar General, India (1988). Report of the Expert Committee on the Population Projections, Occasional paper No.4, Census of India, 1981.

Paqueo V. (1991), “The Relative efficiency of Private and Public Schools in Developing Countries, The World Bank Research Observer, 6, 2 July pp. 205-218.

Prakash. S and Debal P. (1992). "Demographic Transition in India and its Implication for Education", Perspectives in Education, Vol. 8. No. 3-4, pp. 139-153.

PROBE/CDE. (1999). Public Report on Basic Education in India, The Probe Team in Association with Centre for Development Economics, Oxford University Press, New Delhi.

Schenk-Sandberger, Loes (1988). Poverty, and Survival, Kudumbi Female Domestic Servants and Their Households in Alleppey (Kerala), Manohar, Delhi.

Shah. K.R. (1993) “Education: Plea for Higher Plan Allocation”. Research Note Communication, Journal of Educational Planning and Administration, VII, 2 April, pp. 215-222.

Sharma, O.P and R.D. Retherford. (1990). Effect of Female literacy on Fertility in India, Occasional Paper No. 1 of 1990, Office of the Registrar General \& Census Commissioner, India, Ministry of Home Affairs, Govt. of India, New Delhi.

Sivanandan, P (1989). Caste and Economic Opportunity- A Study of the Effect of Educational Development and Land Reforms on the Employment and Income Earning Opportunities of the Scheduled Castes and Scheduled Tribes in Kerala, A Ph.D thesis submitted to the University of Kerala, Centre for Development Studies, Thiruvanathapuram (Unpublished Manuscript) 
State Planning Board (1994). Report of the Expert Committee on School age group Population in 2000 A.D. and its implications on Educational Policy and Planning, Government of Kerala, Trivandrum. (C. Ramakumar, S. Irudaya Rajan and C. Harichandran).

Suri K.C., Bauer and J.R. Rele (1988). Analysis of Work Force in India, Occasional Paper No. 8 of 1988, Office of Registrar General, New Delhi.

Tharakan, P.K.Michael, (1984). "Socio-Economic Factors in Educational Development: Case of Nineteenth Century Travancore", Economic and Political Weekly, Vol XIX, Nos. 45, 46, November 10 and 17.

Tharakan, P K Michael (1990). The Ernakulam District Total Literacy Programme: Report of the Evaluation, Centre for Development Studies, Trivandrum (Typescript).

Thomas J. (1989). Socio- Economic Factors Influencing Educational Standards In a Marginalized Community, A Case Study on the Marine Fisherfolk of Kerala, Unpublished M.Phil dissertation submitted to Jawaharlal Nehru University, New Delhi, Centre for Development Studies, Trivandrum.

Tyagi, P.N. (1991). Education for All, A Graphic Presentation, National Institute of Educational Planning and Administration (NIEPA), New Delhi.

United Nations (1989). Projection Methods for Integrating Population Variables into Development Planning, Vol I, Dept. of International Economic and Social Affairs, United Nations, New York.

Varghese, N.V. (1991), “Technological Changes and Human Resource Development”, In Kothari, V.N (ed.). Issues in Human Capital Theory and Human Resource Development Policy, Himalaya Publishing House, Bombay. 
Visaria, Pravin., Anil Gumber and Leela Visaria (1993). "Literacy and Primary Education in India, 1980-81 to 1991", Journal of Educational Planning and Administration, Vol. VII, Number 1.

World Bank (1991). World Development Report 1991. Oxford University Press, Oxford.

World Bank (1997) Primary Education in India. Washington D.C.

Zachariah, K.C., S. Irudaya Rajan, P.S. Sarma, K. Navaneetham, P.S. Gopinathan Nair and U.S. Misra .(1994). Demographic Transition in Kerala in the 1980s, Monograph Series, Centre for Development Studies, Thiruvananthapuram.

Zachariah, K.C. (1998). Internal Migration: Kerala and other States in India, paper presented in a open seminar at Centre for Development Studies, CDS, Thiruvananthapuram. 


\title{
CENTRE FOR DEVELOPMENT STUDIES
}

\section{LIST OF WORKING PAPERS}

\author{
(From 1991 onwards)
}

MRIDUL EAPEN Hantex: An Economic Appraisal.

September, 1991,

W.P.242

SUNIL MANI Government Intervention in Commercial Crop Development: A Case of Flue Cured Virginia Tobacco.

November, 1991,

W.P.243

K. PUSHPANGADAN Wage Determination in a Casual Labour Market: The Case Study of Paddy Field Labour in Kerala.

January, 1992,

W.P.244

K.N. NAIR \& S.P. PADHI Dynamics of Land Distribution: An Alternative Approach and Analysis with Reference to Kerala.

January, 1992,

W.P.245

THOMAS ISAAC Estimates of External Trade Flows of Kerala - 1975-76 and 1980-81.

March, 1992,

W.P.246

THOMAS ISAAC, RAM MANOHAR REDDY, NATA DUVVURRY Regional Terms of Trade for the State of Kerala.

March, 1992,

W.P.247

P. MOHANAN PILLAI Constraints on the Diffusion of Innovations in Kerala: A Case Study of Smokeless Chulas.

March, 1992,

W.P.248

R. ANANDRAJ Cyclicality in Industrial Growth in India: An Exploratory Analysis.

April, 1992,

W.P.249

T.M. THOMAS ISAAC, RAM MANOHAR REDDY, NATA DUVVURY Balance of Trade, Remittance and Net Capital Flows: An Analysis of Economic Development in Kerala since independence.

October, 1992,

W.P.250

M. KABIR, T.N. KRISHNAN Social Intermediation and Health Transition: Lessons from Kerala,

October, 1992, 
SUNIL MANI, P. NANDAKUMAR Aggregate Net Financial Flows to India: The Relative Importance of Private Loan vis-a-vis Foreign Direct Investments.

August, 1993,

W.P.252

PULAPRE BALAKRISHNAN Rationale and the Result of the Current Stabilisation Programme.

November, 1993,

W.P.253

K.K. SUBRAHMANIAN, P. MOHANAN PILLAI Modern Small Industry in Kerala: A Review of Structural Change and Growth Performance. January, 1994,

W.P.254

DILIP M.MENON Becoming Hindu and Muslim : Identity and Conflict in Malabar 1900-1936.

January, 1994,

W.P.255

D. NARAYANA Government Intervention in Commodity Trade: An Analysis of the Coffee Trade in India.

January, 1994,

W.P.256

K.J. JOSEPH, P. NANDAKUMAR On the Determinants of Current Account Deficits: A Comparative Analysis of India, China and South Korea.

January, 1994,

W.P.257

K.K.SUBRAHMANIAN, K.J. JOSEPH Foreign Control and Export Intensity of Firms in Indian Industry.

February, 1994,

W.P.258

PULAPRE BALAKRISHNAN, K. PUSHPANGADAN Total Factor Productivity Growth in Indian Manufacturing - A Fresh Look.

April 1994,

W.P.259

D. NARAYANA, K.N. NAIR Role of the Leading Input in Shaping Institutions: Tendency in the Context of Irrigation Uncertainty.

May, 1994,

W.P.260

G. MURUGAN, K. PUSHPANGADAN Pricing of Drinking Water: An Application of Coase Two-part Tariff.

December, 1994

W.P.261

MOHANAN PILLAI On the Mexican Crisis.

December, 1995,

W.P.262

SUNIL MANI Financing Domestic Technology Development through the Venture Capital Route.

December, 1995,

W.P.263 
T.T. SREEKUMAR Peasants and Formal Credit in Thiruvithamcore: The State Institutions and Social Structure 1914-1940.

December, 1995

W.P.264

AMITABH Estimation of the Affordability of Land for Housing Purposes in Lucknow City, Uttar Pradesh (India): 1970-1990.

March, 1996.

W.P.265

K. PUSHPANGADAN, G. MURUGAN, K. NAVANEETHAM Travel Time, User Rate \& Cost of Supply: Drinking Water in Kerala, India: June 1996.

W.P.266

K.J. JOSEPH Structural Adjustment in India: A Survey of Recent Studies \& Issues for Further Research,

June 1996

W.P.267

D. NARAYANA Asian Fertility Transition: Is Gender Equity in Formal Occupations an Explanatory Factor?

October, 1996

W.P.268

D. NARAYANA, SAIKAT SINHAROY Import and Domestic Production of Capital Goods from Substitution to Complementarity, October 1996.

W.P.269

\section{NEW SERIES}

W.P. 270 ACHIN CHAKRABORTY On the Possibility of a Weighting System for Functionings December 1996

W.P. 271 SRIJIT MISHRA Production and Grain Drain in two inland Regions of Orissa December 1996

W.P. 272 SUNIL MANI Divestment and Public Sector Enterprise Reforms, Indian Experience Since 1991 February 1997

W.P. 273 ROBERT E. EVENSON, K.J. JOSEPH Foreign Technology Licensing in Indian Industry: An econometric analysis of the choice of partners, terms of contract and the effect on licensees' performance March 1997

W.P. 274 K. PUSHPANGADAN, G. MURUGAN User Financing \& Collective action: Relevance sustainable Rural water supply in India. March 1997.

W.P. 275 G. OMKARNATH Capabilities and the process of Development March 1997

W. P. 276 V. SANTHAKUMAR Institutional Lock-in in Natural Resource Management: The Case of Water Resources in Kerala, April 1997. 
W. P. 277 PRADEEP KUMAR PANDA Living Arrangements of the Elderly in Rural Orissa, May 1997.

W. P. 278 PRADEEP KUMAR PANDA The Effects of Safe Drinking Water and Sanitation on Diarrhoeal Diseases Among Children in Rural Orissa, May 1997.

W.P. 279 U.S. MISRA, MALA RAMANATHAN, S. IRUDAYA RAJAN Induced Abortion Potential Among Indian Women, August 1997.

W.P. 280 PRADEEP KUMAR PANDA Female Headship, Poverty and Child Welfare : A Study of Rural Orissa, India, August 1997.

W.P. 281 SUNIL MANI Government Intervention in Industrial $R \& D$, Some Lessons from the International Experience for India, August 1997.

W.P. 282 S. IRUDAYA RAJAN, K. C. ZACHARIAH Long Term Implications of Low Fertility in Kerala, October 1997.

W.P. 283 INDRANI CHAKRABORTY Living Standard and Economic Growth: A fresh Look at the Relationship Through the NonParametric Approach, October 1997.

W.P. 284 K.P. KANNAN Political Economy of Labour and Development in Kerala, January 1998.

W.P. 285 V. SANTHAKUMAR Inefficiency and Institutional Issues in the Provision of Merit Goods, February 1998.

W.P. 286 ACHIN CHAKRABORTY The Irrelevance of Methodology and the Art of the Possible: Reading Sen and Hirschman, February 1998.

W.P. 287 K. PUSHPANGADAN, G. MURUGAN Pricing with Changing Welfare Criterion: An Application of Ramsey-Wilson Model to Urban Water Supply, March 1998.

W.P. 288 S. SUDHA, S. IRUDAYA RAJAN Intensifying Masculinity of Sex Ratios in India : New Evidence 1981-1991, May 1998.

W.P. 289 JOHN KURIEN Small Scale Fisheries in the Context of Globalisation, October 1998.

W.P. 290 CHRISTOPHE Z. GUILMOTO, S. IRUDAYA RAJAN Regional Heterogeneity and Fertility Behaviour in India, November 1998. 
W.P. 291 P. K. MICHAEL THARAKAN Coffee, Tea or Pepper? Factors Affecting Choice of Crops by Agro-Entrepreneurs in Nineteenth Century South-West India, November 1998

W.P. 292 PRADEEP KUMAR PANDA Poverty and young Women's Employment: Linkages in Kerala, February, 1999.

W.P. 293 MRIDUL EAPEN Economic Diversification In Kerala : A Spatial Analysis, April, 1999.

W.P. 294 K. P. KANNAN Poverty Alleviation as Advancing Basic Human Capabilities: Kerala's Achievements Compared, May, 1999.

W.P. 295 N. SHANTA AND J. DENNIS RAJA KUMAR Corporate Statistics: The Missing Numbers, May 1999. 
This work is licensed under a

Creative Commons

Attribution - NonCommercial - NoDerivs 3.0 Licence.

To view a copy of the licence please see:

http://creativecommons.org/licenses/by-nc-nd/3.0/ 